\title{
Effect of Diet on Depression in Adolescents
}

\author{
Suneeta Pant ${ }^{1}$, Dr. Madhulata Naya ${ }^{2}$
}

\section{ABSTRACT:}

The present study investigated the influence of dietary pattern on depression and also gender effects of depression. A sample of 300 adolescent (150 boys and 150 girls) from Kumaun hills of Uttrakhand state were selected who were taking traditional and mixed food comprise of traditional food with processed food. Dietary pattern were assessed by FFQ and symptoms of depression was tested by IPAT Depression Scale of Krug \& Laughlin. Analysis of data indicates that the dietary pattern do not affect the depression symptom, though gender difference for depressive symptoms was significant. Dietary pattern comprised of local millets and vegetables where the study conducted was the reason for less depressed adolescents

Keywords: dietary pattern, depression, traditional food and mixed food.

It has been a long held belief that diet influences physical and mental health both. There has been a significant increase in the incidence of eating disorder in the past twenty years. Mental health problems are believed to be the result of a combination of factors including age, genetics and environmental factors. One of the most obvious, yet under recognized factor in the development of mental problem is the role of nutrition i.e. changing trend of diet especially in adolescent as it is most vulnerable age group in terms of growth, eating patterns, life style, risk taking behaviors and is environmentally more susceptible.

Eating behaviors common among adolescents are eating away from home, low intake of fruits and vegetables, meal skipping, nutrient poor food items and wide use of fast food and snacks for meal.

Depression and anxiety are critical health problems with increasing prevalence rates. Currently, the best practice for depression and anxiety includes Cognitive Behavior Therapy, psychotherapy, and psychopharmacology. However, there is a growing body of research that indicates that dietary patterns may have an impact on symptoms of depression and anxiety. (Sandra Carey, 2010)

\footnotetext{
${ }^{1}$ Assistant Professor, KVK, Rampur, SVPUA\&T, Meerut, UP

${ }^{2}$ Associate Professor, Kumaun Univ. SSJ Campus, Almora, Uttrakhand
} 
Depression: Depression is an affective disorder that compromises an individual's ability to perform day-to-day tasks due to feelings of sadness, leading to chronic symptoms affecting everyday functioning.

According to Sharp \& Liosky, 2002, depression manifests as a combination of feelings of sadness, loneliness, irritability, worthlessness, hopelessness, agitation, and guilt, accompanied by an array of physical symptoms nutrition can play a key role in the onset as well as severity and duration of depression.

Dietary pattern is food intake pattern of individual. It varies from one individual to other. Gorst - Rasmussen et al. (2011) reported that dietary pattern should reflect the cumulative effect of all foods. Diets remain individual - specific constructs, whereas dietary patterns are population based and usually observational.

Diversity of food is a defining feature of Indian geography and culture. Indian food items vary from region to region, even some time it varies with in the region. Rice, dal and vegetable are taken as meal during lunch, dinner and breakfast. The food habits and preparation varies depending upon the availability of crop and surrounding vegetation. Crops grown in the region and surrounding plant species are the source of raw material for preparation of food recopies (Mehta et al, 2010).

There is rapidly growing scientific interest in the potential for food and specific nutrients to influence various aspects of psychological well being. (Talitha, et.al. 2005) The energy requirement of brain is disproportionately large. When the body is at rest it accounts for approximately $20 \%$ of energy consumption although it comprises only $2 \%$ of body weight. Food can influence human behavior in a number of ways as malnutrition, type of diet, eating habits, pharmacological effects, food allergy, fatty acids deficiency and food additives. Behavior influence of diet is of wide range. It includes attention, conduct disorder and mood (Houghes \& Bryan, 2003).

Partisaul (2006) suggested that omega - 3 fatty acid deficiency has been tied to many conditions including violence, memory problem, hyper activity and depression. Soya been, a rich source of omega - 3 fatty acid and phytoestrogens should be included in diet. In a study conducted by Appleton et al (2007) it was found that depressed mood is associated with fish intake both directly or indirectly as a part of diet. Lakhan and Vieire (2008) reported that lack of certain nutrients essential vitamins, minerals, omega - 3 fatty acid can contribute mental disorder including depression. Ambrosini et al (2009) in a study concluded that high score of psychological symptoms relating internalizing (withdrawal/ depression) and externalizing behavior (delinquency/aggression) were associated with western diet pattern, whereas healthy dietary pattern associated with decrease in symptoms. Jaka et al (2010) in a study found that there is an association between diet quality and adolescent depression. Low intake of nutrient 
dense foods and high intake of high energy nutrient scores foods are related to an increase in the like hood of adolescent being depressed.

The present study investigated the effect of dietary pattern on depression in adolescent in Indian context. Adolescent were chosen for study of depression because this is a period of developmental transition from family. Health habits are initiated in this period because of peer influence and media impact. In India there are very few studies in this field, they are particularly on effect of nutrient on mental health, not the effect of dietary pattern. The objectives of the study are to explore the effect of diet pattern on depression in adolescent and to find out the effect of gender and diet on depression.

\section{OBJECTIVE}

1) To assess level of depression among adolescent taking mixed food and traditional food.

2) To compare groups of adolescent formed on the basis of gender and diet pattern on the variables depression.

3) To study the effect of traditional food and mixed food on occurrence of depression.

4) To compare the level of depression among male and female adolescent.

5) To study interactional effect of sex and dietary pattern on the variables depression.

\section{HYPOTHESIS}

1) Adolescent differentiated on the basis of gender and dietary pattern would differ significantly on their level of depression.

2) Types of dietary pattern would account for developing depression among adolescent.

3) Gender would account for generating depression among adolescent male and female.

4) Gender and dietary pattern would interact significantly for the variable depression.

\section{METHOD}

Sample

The data was collected from the state of Uttarakhand. Three districts were randomly selected from the state, namely Nainital, Almora and Udham Singh Nagar. A sample of 300 adolescents in the age group of 15-17 years was studied for variable depression.

\section{Food frequency questionnaire}

Because of varied food consumption pattern in India, a single FFQ cannot capture variations in dietary intake in population. FFQ was developed by using 24 dietary recall methods. The frequency of food consumption was assessed by 8 - point multiple grid responses ranging from never or monthly to twice daily. Two dietary patterns were identified. The first pattern was 
identified as traditional food pattern including high intake of cereal and pulses including local millets, soybean, fruits and vegetables local uncommon vegetables. The second pattern labeled mixed food pattern includes traditional food with processed food, heavily loaded by high consumption of fried foods, cold drink, Chinese food, junk food.

IPAT DEPRESSION SCALE (PERSONAL ASSESSMENT INVENTORY)

The IPAT Depression Scale (Krug \& Laughlin, 1976) served as the measure of depression. The scale consists of 40 items with true - uncertain - false item format. The scale is scored using either an uncorrected version or corrected version. The corrected raw score, used for data analysis purposes in this study, is the sum of the item scores, 1's and 2's, obtained with a key. Half of the items have ' $a$ ' answer (generally agree or true) as high scoring response and the remaining items have the ' $c$ ' answer (generally untrue or disagree).

\section{PROCEDURE}

24 dietary recalls was carried out to list out the food items generally consumed by the adolescents of the region. From 24 hour dietary recall a FFQ was prepared. Based on responses of the adolescents at 8 point scale, two dietary patterns were identified as traditional food pattern including high intake of cereals and pulses including local millets i.e. finger millet (Eleusine coracana), porso millet (Panicum miliare), and jhangora (Echinochloa frumantacea), pulses i.e. soybean (Glycine $\max$ Linn), and horse gram (Dolichos biflours), vegetables i.e. gathi (Dioscorea bulbifera Linn), lingud (Gleichenia linearis), ogal (Fagopyrum esculent Linn), gaderi (Cococasia esculenta) and bichchu buti (Urtica ardens Link)and in fruits i.e. kilmora (Berberic asiatica), bedu(Ficus roxburghii) and hisalu (Rubus ellipticus).. The second pattern labels mixed food pattern includes traditional food along with processed food, heavily loaded by high consumption of fried food, food items prepared by refined grain, cold drink, Chinese food, junk food and confectionary items.

From filled FFQ adolescents taking traditional food and mixed food were differentiated and listed out. From all the schools of the selected districts 150 girls and 150 boys were selected for administration of psychological test for depression. Out of these 150 boys, 75 boys taking traditional food were studied and rest 75 boys taking mixed food were studied for variable depression. The same were done for rest 150 adolescent girls for testing the variable depression.

The data collected was then statistically analyzed by using ANOVA and result presented and discussed as followed. 


\section{RESULTS AND DISCUSSION}

Table no. - 1 ANOVA on depression

\begin{tabular}{|c|c|c|c|c|c|}
\hline $\begin{array}{l}\text { Source of } \\
\text { variation }\end{array}$ & $\begin{array}{l}\text { Degree of } \\
\text { freedom }\end{array}$ & $\begin{array}{l}\text { Sum of } \\
\text { square }\end{array}$ & $\begin{array}{l}\text { Mean sum of } \\
\text { square }\end{array}$ & F - value & $\begin{array}{l}\text { Level of } \\
\text { significance } \\
\mathbf{0 . 0 5}\end{array}$ \\
\hline $\begin{array}{c}\text { Among } \\
\text { groups }\end{array}$ & 3 & 21.23 & 7.07 & 4.03 & S. \\
\hline A & 1 & 1.47 & 1.47 & 0.84 & N.S. \\
\hline B & 1 & 19.76 & 19.76 & 11.25 & S. \\
\hline AxB & 1 & 0.003 & 0.003 & 0.002 & N.S. \\
\hline Error & 296 & 520.13 & 1.76 & & \\
\hline
\end{tabular}

$\underline{\text { Table no. -2 }}$ Means of Four Groups on Depression

\begin{tabular}{|c|l|l|l|}
\hline Type of food & $\left(\mathbf{B}_{1}\right)$ & \multicolumn{2}{|l|}{ Total } \\
\hline $\mathrm{A}_{1}$ & & 5.56 & 5.82 \\
\hline $\mathrm{A}_{2}$ & 6.08 & 5.71 & 5.96 \\
\hline Total & 6.21 & 5.63 & \\
\hline
\end{tabular}

$\underline{\text { Table no. }-3}$ Critical difference at $5 \%$ level

\begin{tabular}{|c|c|c|c|}
\hline Groups & $\mathbf{N}$ & $\begin{array}{c}\text { Standard error of } \\
\text { difference }\end{array}$ & Critical difference \\
\hline $\mathrm{AB}$ & 75 & 0.23 & 0.46 \\
\hline $\mathrm{A} / \mathrm{B}$ & 150 & 0.13 & 0.26 \\
\hline
\end{tabular}




\section{Effect of Diet on Depression in Adolescents}

\section{DISCUSSION}

From the statistical analysis it was found that groups formed on the basis of dietary pattern and gender differs significantly on depression. From the mean score value it was found that among groups, male that are taking mixed food were affected significantly by symptoms of depression. In Indian context especially in middle class background families, nutrition and cooking are socially constructed as feminine. There is social stigma about cooking and diet that it belongs to women only. Males with lack of cooking skills, which makes food of inconsistent quality, affects nutrients availability, which in turn affects mental and physical health both. They mainly depend on ready to eat food items. Boys have great influence upon their eating habits by the commercial environment, particularly mass media. Adolescent boys are greatly influenced in their eating habits by peers, mass media, social and cultural norms, and lack of nutrition knowledge, while the influence of the family tends to decline. Taste, convenience and affordability were the foremost preference criteria. With increasing fast-food consumption, that of more traditional (and nutrient-dense) food items such as pulses, green leafy vegetables, fruits and milk decreased significantly. It can be said that in adolescent males, taste preferences are a major determinant of food choices. Nutrition knowledge per se is little predictive of eating behaviours, while recognizing that they often have poor food habits.

Samieri et al (2008) studied dietary patterns by a mixed clustering method and analyzed their relationship with depressive symptoms. A "healthy" cluster characterized by higher consumption of fish in men and fruits and vegetables in women, was associated with borderline significance with lower depressive symptoms in women. Men in the "pasta eaters" cluster had higher depressive symptoms. This partially supports our study.

According to Rafael et al (2009), for male students, none of the food consumption groups were associated with perceived stress or depressive symptoms. In females, perceived stress was associated with more frequent consumption of sweets/fast foods and less frequent consumption of fruits/vegetables, which show the contradictory result with the findings of the present study.

There was no significant difference among group formed on the basis of dietary pattern for depression. Mean score value indicates that mixed diet affects the level of depression though not significantly, mixed food as consisted of traditional and processed food. Traditional diet of the region is rich in local millets like barnyad millet, finger millet, foxtail millet, porso millet, kodo and sorghum and pulses like soya bean, pigeon pea, chick pea, lentil, horse gram, french bean, scarlet bean, green gram, black gram, rice bean and cow pea. All these local millets and pulses

are good sources of folic acid, B vitamins, minerals and soybean a rich source of omega -3 fatty acid and are used by the locals.

Local uncommon vegetables like rambans, tarur, lingura, halang, timul, bedu, bichchu ghas, gethi, bathua, lai, methi and spinach does make an important place in the diet of Kumauni people. These are good source of minerals and vitamins essential for mental development. 
Very long chain omega-3 fatty acids (w-3 PUFA) intake and fish consumption have been suggested as protective factors against neuropsychiatric disorders (Sanchez-Villegas eta al 2007, Partisaul 2006). Lakhan and Vieire (2008) reported that lack of certain nutrients can contribute mental disorder including depression. The daily supplements of vital nutrients often effectively reduce the depression, as found in our study. It was reported by several researcher that traditional dietary pattern characterized by vegetable, fruits, meat, fish and whole grain was associated with lower odds for depression and anxiety (Samieri et al 2008, Akbaraly et al 2009, Ambrosini et al 2009, Jaka et al 2010 and Nanri et al 2010). These studies partially support our research.

But for the groups made on the basis of gender there was significant difference. Our findings reveal that males have higher depression whether taking mixed food or traditional food whereas, female have less symptoms of depression. Samieri et al (2008) reported that men and women differ significantly for depressive symptoms. The results of a study done by Murakami et al (2008) indicates that prevalence of depressive symptoms were $36 \%$ for men and $37 \%$ for women, which partially support our study. Boys are more involved in outdoor extracurricular activities as compared to girls. Due to this they cannot take nutritionally adequate diet in time whether it is traditional or mixed. For the study purpose they also bound to reside far away from home, also making it difficult to take nutritional diet, they generally depend on what is available to them easily. There are stereological or socially prescribed masculinities which influences men's health and behavior. Looking at patterns of eating behaviour in situations in which young people are likely to be able to make personal choices may provide a useful complement to assessing dietary intake. Amongst adolescents this relationship may be mediated in part by snacking behaviour, since a disadvantaged home life has been linked to less regular meal patterns and a higher consumption of sweet and fatty snacks.

The result of interaction among dietary pattern and gender do not differ significantly for depression. Food consumption frequencies vary by country and gender, as did depressive symptoms and perceived stress (Rafael et al, 2009).

'The results suggest that traditional diet afford protection against symptoms of depression, while diet rich in junk food and processed food increase vulnerability. The findings suggests that healthy eating policies will generate additional benefit to health and that should be considered helpful in prevention of depression which is prevailing among adolescent.

\section{CONCLUSION}

Major findings of the study are:

1) Depression did not significantly affected by dietary pattern, but gender difference was significant for depression.

2) Male adolescents were more prone to depression than female adolescents.

3) Male adolescents that are taking mixed food were affected significantly by symptoms of depression. 


\section{Effect of Diet on Depression in Adolescents}

\section{REFERENCES}

Akbaraly, T.N., Brunner, E. J., Ferrie, J. E., Marmot, M. G., Kivimaki, Mika, Archana Singh Manoux. (2009). Dietary pattern and depressive symptoms in middle age: the Whitehall II study, The British Journal of Psychiatry, 195 (5), 408 - 413.

Ambrosini, G.L., Oddy, W.H., Robinson, M. O’Sullivan, T.A., Hands, B.P. and De Clark, N.H. et al. (2009). Adolescent dietary pattern with life style and family - socio economic factors. Public Health Nutrition, 12(10), 1807-1815.

Appleton, K.M., Woodside, J.V., Yarnell, J.W., Arveiler, D., Haas, B., Amouyel, P., Montaye, M., Ferrières, J., Ruidavets, J.B., Ducimetiere, P., Bingham, A. and Evans, A. (2007). Depressed mood and dietary fish intake: direct relationship or indirect relationship as a result of diet and lifestyle? J. Affect. Disord., 104(1-3), 217-23.

Hughes D. and Bryan J. (2003). The assessment of cognitive performance in children: consideration for detecting nutritional influences. Nutritional Reviews, 61 (12), 423-422.

Jacka, F. N., Peter J. K., Eva R.L., Michael B., George C. Petton, J., W. T. and Joanne W.W. (2010). Association between diet quality and depressed mood in adolescent, results from Australian healthy neighborhood, Australian and New Zealand J. of Psychiatry, 44, 435 442.

Kurg,S.E. and Laughlin, J.E. (1976). Hand book for the IPAT Depression Scale. Rupa Psychological Centre. Bhelupura, Varanasi.

Lakhan, Shaheen E. and Vieira, Karen F. (2008). Nutritional therapies for mental disorders. Nutrition Journal, 7(2), 7-2.

Mehta, P.S., Negi, K.S. and Ojha, S.N. (2010). Native plant genetic resources and traditional food of Uttarakhand Himalyas for sustainable food security and livelihood. Indian J. of Natural Products and Resources, 1(1), 89-96.

Murakami, K., Mizoue, T., Sasaki, S., Ohta, M., Sato, M., Matsushita, Y. and Mishima, N.(2008). Dietary intake of folate, other B vitamins, and omega-3 polyunsaturated fatty acids in relation to depressive symptoms in Japanese adults. Nutrition, 24(2), 140-7.

Nanri A., Kimura Y., Matsushita Y., Ohta M., Sato M., Mishima N., Sasaki S. and Mizoue T. (2010). Dietary patterns and depressive symptoms among Japanese men and women. Eur J Clin Nutr., 64(8), 832-839.

Partisaul, H. B. (2006). Dietary influences on anxiety and aggression. Symposium. International Society for Research on Aggression. XVII World meeting.

Rafael, T. M., Walid, E. I. A. and Annette, E. M. (2009) .Food consumption frequency and perceived stress and depressive symptoms among students in three European countries, Nutrition Journal, 8, 31 . 
Rasmussen - Gorst, Anders, D., Christina C., Claus, D., Thomas, S. and Overvad, K. (2011). Dietary Pattern Analysis. American Journal of Epidemiology, 173(10), 1109-1110.

Samieri, C., Jutand, M.A., Feart, C., Capuron, L., Letenneur, L. and Barberger- Gateau, P. (2008) Dietary patterns derived by hybrid clustering method in older people: association with cognition, mood, and self-rated health. J Am Diet Assoc., 108, 1461-1471.

Sanchez-Villegas, A., Henríquez, P., Figueiras, A., Ortuño, F., Lahortiga, F. and MartínezGonzález, M.A.(2007). Long chain omega-3 fatty acids intake, fish consumption and mental disorders in the SUN cohort study. Eur. J. Nutri. 46(6), 337-346.

Sandra, C. G. (2010). Dietary patterns and their effect on depression and anxiety among healthy adults by Psy.D. Adler School of Professional Psychology, 101, 3452688.

Sharp, L. K. and Lipsky, M. S. (2002). Screening for depression across the lifespan: A review of measures for use in primary care settings. Am Farm Physician, 66(6), 1001-1009.

Talitha, B., Eva, K., Janet, B. (2005). Effect of saccharides on brain function and cognitive performance. Nutrition Reviews, 63(12), 409-418. 